\title{
Continuing Friendship in the Face of European Destruction and European Construction: The European Conference on Psychosomatic Research
}

\author{
Wolfram Schüffel \\ University of Marburg, Marburg, Germany
}

(1) 'Man is a social animal living in a human culture' $[1,2]$ : The European Conference on Psychosomatic Research and its culture are built upon the foundation of friendship, initiative, and lasting commitment

The European Conference on Psychosomatic Research (ECPR) is the oldest European psychosomatic organization. It was founded in London on April 22-23, 1955 and in Amsterdam on April 17-21, 1956 by two doctors, Johannes Juda Groen (Amsterdam) (fig. 1) and Archibald Denis Leigh (London) (fig. 2). Since 1970 (Knokke, Belgium), the ECPR has been taking place in years with even numbers and usually at the end of the summer semester. The hosts are highly regarded representatives of psychosomatics in Europe, and the meetings take place where they work. The hosts are supported by their staff and by regional and national work groups. This means that the ECPR is not a registered association.

The participants at the meetings describe themselves as colleagues and friends who have a common aim, that is research in the field of holistic medicine that aims to treat the whole person. Since 1955, there have been 29 conferences, the most recent one having taken place in Aarhus, Denmark in 2012.
Will there be another 29 conferences? What would a 58th ECPR conference in 2071 be like? As the author of this text, I would say that the history of the ECPR is the history of a friendship between two men - two pioneers of psychosomatics in Europe. It is the history of an interpersonal relationship in postwar Europe. This relationship continued even after the death of the two men. They are Joannes Juda Groen (1903-1990) and Archibald Denis Leigh (1915-1998). J.J. Groen was a specialist in internal medicine; first he was Professor of Internal Medicine and Chief Physician at the Wilhelmina Gasthuis, University of Amsterdam, later he became a Professor of Internal Medicine at the Medical School of the Hadassah University in Jerusalem, and finally, when he was an Emeritus Professor, head of a psychobiological unit. Involved in the latter was also J. Bastiaans, a former pupil of his, and a Professor of Psychiatry at the University of Leiden. Denis Leigh was a neurologist, who sometimes also practised as a neurosurgeon and later - and most importantly - as a psychiatrist. He was consultant psychiatrist at the Maudsley and Bethlem Hospital in London. At the same time, he was an inspiring university and college lecturer (Royal College of Psychiatrists).

\section{KARGER}

E-Mail karger@karger.com www.karger.com/pps
(C) 2013 S. Karger AG, Basel

0033-3190/13/0824-0273\$38.00/0
Prof. Wolfram Schüffel Kaffweg 17a DE-35039 Marburg (Germany)

E-Mail wolfram@ @chueffel.de 


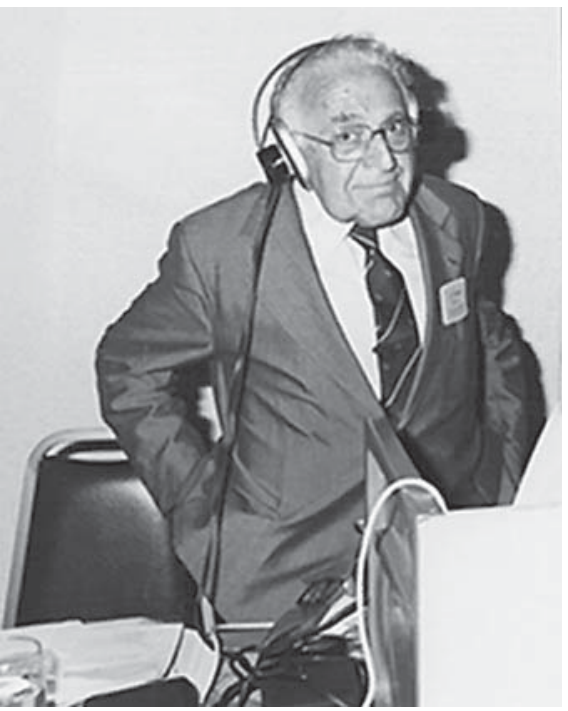

Fig. 1. J.J. Groen.

It is unusual for an association, based on personal relationships, to be effective across European medical disciplines for longer than half a century without being a registered association. It is also unusual for an association of this kind to be sustained exclusively by the initiative and lasting commitment of its organizers and attendees. How has this come about?

I would say that the history of the ECPR was determined by the reaction of these two men to the situation in postwar Europe. This period was marked not only by injury and loss, but also by the feeling that the threat to humanity represented by fascism had been overcome and by a sense of having been liberated. Fifty colleagues from twelve nations came together, from countries which had fought bitterly for survival, such as Great Britain, from countries which were now freed from the threat of fascism, such as Belgium, Denmark, France, Greece, Luxemburg, Norway, and Poland, and from two countries still under a fascist regime, that is Spain and Portugal. Lastly, there were colleagues from countries where fascism had developed, i.e. Germany, Austria, and Italy, and where some had been persecuted and survived the concentration camps.

After the meetings in 1955 and 1956, there followed meetings in Copenhagen 1957 (V. Lunn), Hamburg 1959 (A. Jores), Madrid 1961 (J.J. Lopez-Ibor), Athens 1964 (G.S. Philipopoulos), Rome 1967 (F. Antonelli), and finally Knokke 1970 (R. Pierloot). Europe's borders were open. In this situation the ECPR developed into a European success story as has been described by Pierloot [3] and by Freyberger [4].

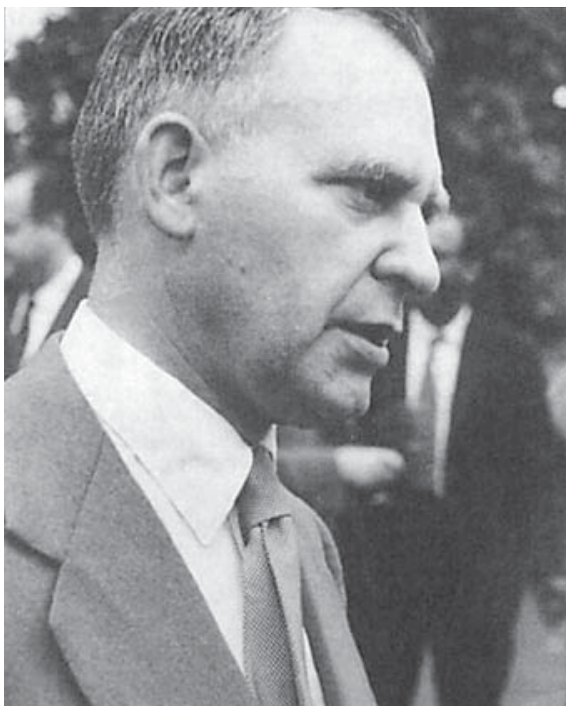

Fig. 2. D. Leigh.

(2) 'From his (man's) conception and during his development in utero he belongs to cultural (sub)groups, the first of which is the family into which he will be born... The young human has to live during the long period of his immaturity (longer than most animals known to us) in an inescapable intercommunication with his elders and peers' [1]: The European Conference on Psychosomatic Research as an ongoing communication on complaints, symptoms, signs, and indications of illness and health

The purpose at that time was to establish an exchange of information between all medical disciplines in order to achieve humane and environmentally appropriate practices in medicine which can be briefly defined as medicine that has been psychosomatically researched. The participants were already stressing the advantages of personal contact and an informal atmosphere. I would say now, with reference to the relationships and situation criteria I have mentioned above, that it is important to include any third person in an existing relationship, so that he/she feels supported and can begin to support others. As the representative of many colleagues in the years between 1955 and 2012, I would like to describe how I was accepted as a third person in the relationship between member and the community. This was in Knokke in Belgium in 1970 during the eighth meeting of the ECPR under the chairmanship of R.A. Pierloot (Leuven). At the time I was a 32-year-old assistant physician at the University Clinic for Internal Medicine in Ulm, Germany, under the directorship of Thure von Uexküll. I was training to be a spe- 
cialist in internal medicine with psychosomatic medicine as my main speciality. During this eighth meeting I happened to meet colleagues I knew only from my reading of the literature. Nevertheless, they accepted me into their community without question and - in spite of being German - I felt supported. Groen made the most lasting impression on me and I felt accepted and supported. He was a short, stocky man, not much more than five feet tall, who was already struggling with hearing loss, something that I had the impression he sometimes also turned to his advantage. He displayed an extraordinarily lively curiosity, and in discussions he was quick to pick out critical points and request clarification. Disregarding the usual hierarchy, we talked to one another, paying no attention to the fact that he was a world-renowned professor of internal medicine and I was a naive and inexperienced young intern. We spoke about patients and their complaints and how these become symptoms and indications not only of an illness but also of health. Groen's formulations about dealing with symptoms and their interpretation are fixed in my memory. I tried to understand how almost dichotomic symptoms and signs could be filtered out from the complaints made by the patient. It was not until much later that I recognized a significant difference within Western terminologies: when describing complaints, the Anglo-Saxon vocabulary makes use of two terms, namely symptom and sign, according to whether it is the doctor or the patient describing the complaints. This differentiation is not made in German, where the term symptom is used by both patient and doctor. This has far-reaching consequences both in theory and in practice [5].

(3) '(Man intercommunicates) even with those who frustrate him by their domineering and with whom he clashes in conflict, because they are the same as those on whom he is otherwise dependent for his security and protection' [1]: The European Conference on Psychosomatic Research as a forum for engaging in discussion on values: how to make medicine a science of humanity?

Groen stated that human beings are 'social animals' who live in a human culture. Just a few years previously, Orwell's Animal Farm [6] had appeared, a reflection of a totalitarian world and what it produced - fear, depression, shame, and resulting illness. Groen knew Orwell's work very well and calmed those fears. He pointed out that psychosomatics should be dealing with development in the womb, indeed with the time before conception where the focus is on 'love and hate'. He chose to put the word 'love' first.
Man is a social animal living in a human culture. From his earliest development he has to adapt to living in a socio-cultural environment. From his conception and during his development in utero (sic) he belongs to cultural (sub)groups, the first of which is the family into which he will be born... The young human has to live during the long period of his immaturity (longer than most animals known to us) in an inescapable intercommunication with his elders and peers, even with those who frustrate him by their domineering and with whom he clashes in conflict, because they are the same as those on whom he is otherwise dependent for his security and protection. This increases the chances of the development of ambivalence and insecurity, as the same person can be both friend and enemy, comrade and competitor. [1]

Groen formulates contrasting methods of dealing with complaints by using a comparison. He was able to do this because of his wide experience which included his experiences in Israel where, as a doctor, he dealt on a regular basis with patients from over a hundred different ethnic backgrounds. When comparing Arabic and Central European approaches, he says the following:

How important cultural factors are for the concept even of what constitutes a disease may be illustrated by the following: I was once watching the treatment of Bedouin patients by their government doctor in a clinic in the Negev Desert. Among them was a 25-yearold woman. Her story was a follows: 'Help me o doctor, I am so upset, I am so unhappy. I am married 6 years and all was well with me. I have 4 children and I never once had to wash' (meaning that she never had a menstruation during this period; apparently she had gone from pregnancy to gestation to pregnancy etc.). 'But now I have had to wash already 4 times. Please help me. I am unhappy. My womb has closed.' For this woman menstruation was an 'impurity', as described in the Bible, a missed pregnancy, a sign that there was something wrong, something ill [1].

\section{Groen asks us to consider the following:}

Compare this with modern Western women who all too often get frightened and come to the doctor in despair because they do not have their period! ... Fascinating transcultural differences exist in the frequency of so-called functional diseases like migraine, impotence, frigidity and constipation. Within the Western culture these disorders are more common among the well-to-do 'educated' classes than among the socially 'lower' stratum of society. They are definitely rarer in 'primitive' and Eastern cultures than in the west. The same holds for dysmenorrhoea and vomiting during pregnancy, which is, for example, almost unknown among the Bedouin of the Negev Desert [1].

With regard to this, Groen makes the following comment: 'It is as if they (patients of Eastern cultural groups, whether Jew or Arab, cannot distinguish between psychic and somatic signs and symptoms.' He adds: 
Perhaps we should formulate it so that the distinction between mind and body, which originated in the classical Greek philosophy, infiltrated via St. Paul and Descartes into Western thought and science, and has now become part even of the everyday expressions of Western man about himself, has never penetrated into the Eastern way of 'Menschbetrachtung', which is still 'wholistic' and without the dichotomy of mind and body [1].

This was a comment that I did not hear during my time as a medical student, nor did I hear it later during clinical practice. These were statements with a complexity and focus that I had not heard in clinics in other countries and cultures either.

Groen was cautious about talking about the past (at least while he was in my presence). I almost never heard him speak of how he had been in hiding and survived the Nazi German occupation of the Netherlands. However, he did speak about how looking at the past can help to sharpen our view of today's world and of the world of tomorrow:

We have elsewhere described how during the Nazi-German occupation of the Netherlands from 1940-1945, a marked change occurred in the frequency of certain diseases, which we related to the marked change in the structure of the Dutch society during that period. Especially during the 'famine winter' of 1944-1945 when there was an alarming increase in starvation, famine oedema, tuberculosis, dysentery, diphtheria, there was an amazing diminution in the prevalence and severity of diseases like peptic ulcer, asthma, ulcerative colitis, migraine, hypertension and coronary heart disease. The same phenomena were observed among the inmates of the concentration camps. This peculiar 'shift' in disease pattern we explained by the specific relation which apparently existed between different types of stress and the ensuing disease. The socio-cultural stresses of the pre-war Netherlands society, with its accent on controlled behaviour in reaction to nonviolent interhuman conflicts, were entirely different from the stresses of famine and brutal cruel persecution which reigned at that time. [1]

This view is characteristically imbued with the spirit of enlightenment, and he sees himself as a kindred spirit of Spinoza (1632-1677). He summarized briefly, in two sentences, the development of Europe and the Western World in a way which has never been achieved again: it was not until the late 18th century that medicine became an independent course of university study with the integration of natural sciences into medicine by Dr. H. Boerhaave in Leiden (1668-1738) and the subsequent division of medical studies into preclinical and clinical segments. The task now is to make medicine a science within the humanities. In this connection, his efforts to encourage new approaches were outlined in a paper dedicated to Groen [7]. He once commented on the success- es of medicine as follows: it is open to question whether today's increased life expectancy can be ascribed to medicine. I was able to demonstrate that there was a decrease in mortality rates following the introduction of soap. (This remark did not only win him friends in medical circles, but he seemed to have taken this in his stride.) Groen thought about the place individual disciplines and subdisciplines should occupy within science. Before the Second World War, he had himself presented groundbreaking papers in the field of biochemistry. He was the first researcher in the world to establish the biological activity of insulin (in the rat diaphragm) and spent a period of time researching in Boston, Mass. with E.P. Joslin, the best-known diabetologist of the time. After the war, he devoted increasing attention to psychosocial questions in medicine (see the comparable career of D. Leigh below). Here his focus has always been on the patient. He reported on a meeting with $\mathrm{K}$. Bykow, one of the most distinguished pupils of I. Pavlow, whom he visited in Moscow in the early 1950s in the company of Stewart Wolf. When the discussion threatened to turn ideological - it was during the cold war period - Groen suggested the issues should be discussed on the basis of a specific case study. In this way the participants found a solution that all parties could accept. Unfortunately, he never met M. Balint, as far as I am aware. He would have agreed with Balint on the fundamental issues of relational, patient-doctor-focussed medicine.

The reference to Moscow can here serve as a link to a discussion on Archibald Denis Leigh and his significance for the ECPR. I never met him personally, and so can only talk about him on the basis of second-hand knowledge. However, I sense a strong emotional affinity with him thanks to the influence of Groen. From Leigh's curriculum vitae, and from Groen's reports, we can see that Leigh was committed to a world that he saw as a developing entity to be continually fought for. This applies equally to the collective political and social world and to the individual somatopsychic world. With regard to the former, as secretary of the World Council of Psychiatry, he wanted the Soviet Union and its psychiatrists to remain within the international professional organization during the years of the Cold War. He was well aware that Soviet colleagues were misused as henchmen of the degenerate communist regime, and that they themselves also colluded in this misuse. On the other hand, in his native Britain, where he was a respected citizen and active participant in the medical sector, he uncovered the improper use of violence in the case of IRA prisoners and was successful in discussing this in public. 
He personally - during the war on the Japanese front in the Far East - did valuable work as a doctor and neurosurgeon treating soldiers in Burma. He was then ordered back home to build up treatment centers for patients with brain injuries. He became involved in individual clinical cases to such an extent that his descriptions of traumatic olfactory disorders are still cited today. His talent for clinical examination must have been unsurpassable. He was able to describe for the first time a disease in a 6-month-old baby, a disease that now bears his name: Leigh's disease. It is a mitochondrion-related illness that can only be recognized through very exact clinical observation. The reports repeatedly emphasize how extremely rare this illness is. Leigh filtered it out on the basis of his broad clinical experience and critical objectivity in the face of various differential diagnoses. On the same level as this achievement is his work as an expert witness in the case involving the German Günther Podola, who in 1959 stood accused of capital murder for shooting and killing a police sergeant. This crime carried the death penalty and the Judge Edmund-Davies, later Lord Edmund-Davies, had to sentence him to death. Throughout the proceedings, Podola claimed he could not remember having committed the crime but Leigh diagnosed him as feigning hysterical amnesia, thus accepting responsibility in the most demanding of situations.

The Judge was later asked about this in a recorded interview about his life. This Judge had also been chairman of the Aberfan Tribunal [8]. On October 21, 1966, 116 children and 28 adults died in their homes and in a school in Aberfan in Wales when a colliery spoil tip, already known to be unsafe, collapsed. Concerns raised about the tip had largely been ignored. The deep emotion of this judge, himself a Welshman, was clearly visible when he was asked about both these cases. It is now impossible to tell which of them affected him more. In 1965, that is only a few years after the Podola trial, the death penalty was abolished in Great Britain.

This serves as an appropriate example of Archibald Denis Leigh's high moral integrity. He did not shrink from engaging in discussions on values. Later I will refer to his fight for the fundamental values of free artistic expression in the case dealing with the novel Lady Chatterley's Lover.
(4) '(By trusting intercommunication man) increases the chances of the development of ambivalence and insecurity, as the same person can be both friend and enemy, comrade, and competitor' [1]: The European Conference on Psychosomatic Research as reflecting European Destruction and Construction while communicating globally on issues relating to holistic medicine

The inception and the first 15 years of the ECPR from 1955 to 1970 can be appropriately described as a special chapter in a period that brought destruction and construction in Europe. I have chosen this expression deliberately. It was the motto of the 13th dOCUMENTA art show, 2012, in Kassel, Germany [9], one of the most important art exhibitions in the world and its concern with science, craft, and art makes it of interest to doctors addressing psychosomatic disorders and to all those involved in the healing professions.

I will comment in a later chapter in this series on how colleagues of those two men, Leigh and Groen, succeeded in gathering men and women around them who tried to realize and then succeeded in realizing the idea of holistic medicine during the period following the European catastrophe of 1945. There will be four parts to the series. The second part will deal with the 9th ECPR in 1972 in Vienna under the chairmanship of E. Ringel. Particularly important innovations in the field of psychosomatics will be discussed: integrated psychosomatic medicine, consultation-liaison, alexithymia, and the intensification of a transatlantic, global exchange.

It is impossible to overestimate the importance of the fact that the International College of Psychosomatic Medicine (ICPM) was founded in Guadeloupe in 1969. Cofounders, among others, were the Japanese Y. Ikemi (Fukuoka), a leader in psychosomatics in the Far East. His senior physician H. Ishikawa (later in Tokyo) [10] made personal contact with the ECPR in 1970.

The ECPR developed in 1970 into a forum for the intense discussion about the future development of psychosomatic medicine in Europe [11], while maintaining contact with the world outside Europe [12]. Psychosomatic medicine in Europe exhibits a distinctive development of its own. However, it clearly is part of a global development towards the health of mankind. 


\section{References}

1 Groen JJ: Influence of social and cultural patterns on psychosomatic diseases. Psychother Psychosom 1970;18:189-215.

2 Groen JJ: Clinical Research in Psychosomatic Medicine - A Collection of Papers by J.J. Groen. Assen, Van Gorcum, 1982, p 27.

-3 Pierloot RA: Recent research in psychosomatics. Introduction. Psychother Psychosom 1970;18:1-11.

4 Freyberger $\mathrm{H}$ : Topics of psychosomatic rearch; in Freyberger $\mathrm{H}$ (ed): Proceedings of the 9th European Conference on Psychosomatic Research, Vienna, Austria, April 25-28, 1972. Basel, Karger, 1973, p VIII.
5 Schüffel W: Western and Eastern thinking as shown in the practice of psychosomatic medicine. International Congress Series. Amsterdam, Elsevier, 2006, vol 1287, pp 38-44.

6 Orwell G: Animal Farm. New York, Harcourt, Brace \& Company, 1946.

7 Schüffel W, Pauli HG: Educating the physician; in von Uexküll T (ed): Psychosomatic Medicine. Munich, Urban \& Schwarzenberg, 1997, pp 876-894.

8 Report of the Tribunal Appointed to Inquire into the Disaster at Aberfan on October 21st, 1966. London, Her Majesty's Stationery Office, 1967.

9 dOCUMENTA (13), Destruction and Construction; in Christov-Bakargiev C, Anastas A, Berardi F (eds): Catalogue. Cologne, Hatje Cantz, 2012.
10 Ishikawa H: Emotion, and rhythm of breathing and heart beat. Psychother Psychosom 1970;18:248-253.

11 Fink P: Towards a new agenda: cross-disciplinary approach to psychosomatic medicine. 29th European Conference on Psychosomatic Research (ECPR). 15th Annual Scientific Meeting of the European Association for Consultation-Liaison Psychiatry and Psychosomatics (EACLPP), Aarhus, June 27-30, 2012.

12 Fava GA: International advanced training workshop psychosomatic medicine. ICPM Int College Psychosom Med, Rome, November 11-12, 2011.

\section{Erratum}

In the article by Fiedorowicz et al., 'Vasculopathy Related to Manic/Hypomanic Symptom Burden and First-Generation Antipsychotics in a Sub-Sample from the Collaborative Depression Study', Psychother Psychosom 2012;81:235-243 (DOI:10.1159/000334779), the first entries in the table headings of tables 3 and 4 are wrong, they inappropriately report $\chi^{2}$ in the place of the $\beta$ parameters.

The correct table headings of tables 3 and 4 should read:

\begin{tabular}{llllll}
\hline & $\beta$ & $\mathrm{SE}$ & $\mathrm{t}$ & $p$ \\
\hline
\end{tabular}

